\title{
A criação do Colégio de Pedro ll e seu impacto na constituição do magistério público secundário no Brasil
}

\author{
Ana Waleska P. C. Mendonçal \\ Ivone Goulart Lopes' \\ Jefferson da Costa Soares' \\ Luciana Borges Patroclo'
}

I- Pontifícia Universidade Católica do Rio de Janeiro, Rio de Janeiro, RJ, Brasil.

Contatos: awm@puc-rio.br; jefics@yahoo.com.br; ivone.goulart@hotmail.com; lupatroclo@yahoo.com.br

\section{Resumo}

Este trabalho se vincula a uma pesquisa mais ampla que tem como objeto de estudo o processo de construção de uma identidade profissional específica por parte de um segmento da categoria docente - o magistério público secundário - no Brasil, constituindo-se como um primeiro produto coletivo do grupo de investigação. A referida pesquisa parte de um recorte institucional e toma como alvo de estudo o Colégio Pedro II, que foi criado pelo governo imperial em 1837 e que, após a República, é mantido pelo governo federal, conservando, até meados do século XX, o caráter de instituição modelar para todo o ensino secundário brasileiro. 0 texto está dividido em duas partes. Na primeira, propõe-se a identificar o programa institucional que informou a criação do Colégio de Pedro II. Na segunda, desenvolve um estudo preliminar sobre a primeira geração de professores do Colégio, nomeados entre 1838 e 1847, buscando estabelecer uma caracterização geral: as formas de recrutamento; a distribuição pela diferentes disciplinas; as categorias docentes previstas nos estatutos de 1838; as trajetórias internas no Colégio, inclusive o tempo de docência na instituição; a formação acadêmica; a experiência docente anterior; as outras instituições educacionais/culturais em que atuavam, entre outros aspectos. As principais referências teóricas são os trabalhos de dois sociólogos franceses que se debruçaram sobre o processo de construção da identidade profissional docente, a saber: François Dubet e Claude Dubar.

\section{Palavras-chave}

Professores secundários - Brasil - Colégio Pedro II. 


\title{
The establishment of Colégio Pedro II and its impact on the formation of secondary public teaching in Brazil
}

\author{
Ana Waleska P. C. Mendonça' \\ Ivone Goulart Lopes' \\ Jefferson da Costa Soares' \\ Luciana Borges Patroclo
}

\begin{abstract}
This work is linked to a broader study whose object of study is the process of building a specific professional identity of a segment of teachers - public secondary teachers - in Brazil. It is the first collective product of our research group. Such research starts from an institutional outline and studies Colégio Pedro II (Pedro II Secondary School), which is created by the imperial government in 1837 and, after the Republic, is maintained by the federal government and keeps, until the mid-twentieth century, the character of model institution of all secondary education in Brazil. The text is divided into two parts. In the first one, we intend to identify the institutional program that informed the creation of Colégio Pedro II. In the second part, we develop a preliminary study on the first generation of Colégio's teachers, appointed from 1838 to 1847, and we seek to establish a general characterization: forms of recruitment; distribution by different disciplines; teacher categories provided in the statutes of 1838; the trajectories inside Colégio, including the time teaching at the institution; academic qualifications; previous teaching experience; the other educational/cultural institutions where they worked, among other aspects. The main theoretical references are the studies of two French sociologists who have looked into the process of construction of teacher professional identity: François Dubet and Claude Dubar.
\end{abstract}

\section{Keywords}

Secondary teachers - Brazil - Colégio Pedro II.

I- Pontifícia Universidade Católica

do Rio de Janeiro, Rio de Janeiro,

RJ, Brasil.

Contacts:awm@puc-rio.br;

jefics@yahoo.com.br;

ivone.goulart@hotmail.com;

lupatroclo@yahoo.com.br 
Este trabalho se vincula a uma pesquisa mais ampla que tem como objeto de estudo o processo de construção de uma identidade profissional específica por parte de um segmento da categoria docente - o magistério público secundário - no Brasil. A pesquisa tem um recorte institucional e a instituição escolhida para o estudo é o Colégio Pedro II, que foi criado pelo governo imperial em 1837 e que, mesmo após a implantação do regime republicano no Brasil, em 1889, passado um período inicial em que se configurou como Ginásio Nacional (1890-1911), retoma sua denominação original e permanece sendo mantido pelo governo federal. Até meados do século XX, o Colégio exercia o caráter de instituição modelar para todo o ensino secundário brasileiro. ${ }^{1}$

Pretende-se estudar a maneira como se configuraram os quadros docentes dessa instituição em dois momentos significativos do processo de institucionalização do ensino secundário no Brasil. 0 primeiro momento se constitui nos anos iniciais de funcionamento do Colégio de Pedro II, ao longo do Império (18371889). Cumpre ressaltar que é com a criação do referido Colégio que a própria denominação de ensino secundário passa a ter curso legal entre nós. 0 segundo momento se constitui no período que se estende dos anos 1920 aos anos 1940, sendo delimitado por três reformas (Rocha Vaz, em 1925; Francisco Campos, em 1932; e Gustavo Capanema, em 1942) que consolidaram o processo de institucionalização do ensino secundário brasileiro, com a extinção definitiva dos exames parcelados de disciplinas isoladas e sua estruturação em dois ciclos. Foi também ao longo desse período que se institucionalizou a formação dos professores secundários, com a criação das faculdades de filosofia, e que se equacionou, pela primeira vez, a questão do registro profissional desses professores.

0 presente trabalho se refere à primeira década de funcionamento do Colégio de Pedro II

1- Na verdade, as denominações atribuídas ao Colégio ao longo do tempo foram várias. A esse respeito, ver DORIA, 1997; ANDRADE, 1999; VECHIA; LORENZ, 1998; GASPARELLO, 2004. e se remete, particularmente, aos anos de 1837 a 1847. 0 marco inicial se justifica tendo em vista que o Colégio é criado em 1837 e começa a funcionar no ano seguinte, com base em um Regulamento aprovado em janeiro de 1838 e que já em 1841 sofre sua primeira alteração. Estamos diante de um ensino secundário e, especificamente, de uma instituição de ensino em processo de construção. 0 marco terminal se estabeleceu em razão do registro, no ano de 1847, de um primeiro concurso para seleção de professores a serem nomeados para o Colégio. Esse marco nos permitiu definir o que estamos chamando de a primeira geração $o^{2}$ de professores do Colégio.

Tal referência foi encontrada em Memória histórica do Colégio de Pedro Segundo (18371937), texto escrito por Escragnolle Doria, professor de história universal e história do Brasil no Colégio, entre 1906 e 1910, que se remete a esse processo de seleção nos seguintes termos:

Até então o ingresso no corpo docente fora feito mediante livre nomeação do governo. 0 concurso de 1847 tornou-se no Colégio o primeiro indício de concurso, embora de títulos, o governo imperial acostumado ao ad libitum das designações desde 1838. (DORIA, 1997, p. 65)

Os cinco candidatos que se apresentaram ao Ministro do Império, o Senador Alves Branco, tiveram seus requerimentos encaminhados ao Reitor do Colégio, Joaquim Caetano, que procedeu à seleção. Parece-nos interessante transcrever as informações do Reitor sobre o candidato selecionado, pois elas são indicativas dos critérios de escolha:

João Baptista Calogeras - Possui bem as línguas e as literaturas Grega, Latina, Francesa, Italiana e Inglesa; é dotado de

2- Somos plenamente conscientes da dificuldade de se trabalhar com a categoria de geração. Optamos por utilizá-la na perspectiva de Sirinelli (2006), entendendo-a como uma construção do historiador. 
raro talento, de uma cabeça filosófica e grande facilidade de elocução e tem se aplicado com muito mérito e proveito ao estudo da História. Pelo que o considero capaz de reger a cadeira com indisputável superioridade. Esteve dois anos em Bolonha e nove em Paris. (apud DORIA, 1997, p. 66)

Os primeiros atos legais referentes ao Colégio são bastante omissos a respeito tanto de critérios quanto de mecanismos para a seleção de professores. 0 Decreto-Lei de 2 de dezembro de 1837, que converte "o Seminário de S. Joaquim em collegio de instrucção secundaria com a denominação de Collegio de Pedro II", apenas estabelece genericamente que haverá os professores que forem precisos para as disciplinas previstas no artigo $3^{\circ} \mathrm{e}$ prevê a possibilidade de chamar para exercício no Colégio os professores públicos da Corte de disciplinas avulsas (art. 50), permitindo-lhes acumular os vencimentos já recebidos com os vencimentos variáveis pagos aos demais professores. Esses professores, remanescentes dos antigos professores régios, eram recrutados por meio de concurso.

Igualmente, os primeiros estatutos do Colégio, contidos no Regulamento de 31 de janeiro de 1838, estabelecem genericamente, em seu artigo 12, que “os professores serão nomeados pelo Governo, dando preferência aos empregados do Colégio que se acharem habilitados", sem que sequer se especifique em que consiste essa habilitação.

A realização de concursos constitui, sem dúvida, um marco importante no processo de profissionalização docente e configurou-se historicamente como um dos primeiros mecanismos utilizados pelo Estado para a certificação dos professores. No entanto, no caso do Colégio Pedro II, ela de fato só se tornaria obrigatória por efeito do Decreto $\mathrm{n}^{\circ}$ 1331-A, de 17 de fevereiro de 1854, que regulamentou a instrução primária e secundária do Município da Corte e estabeleceu os "exames de capacidade para o magistério".
Nosso trabalho estará dividido em duas partes. Na primeira, propomo-nos a identificar o programa institucional que informou a criação do Colégio de Pedro II. Desse ponto de vista, nossa referência central será o sociólogo francês François Dubet na análise que desenvolve sobre a profissão docente em seu livro Le declin de la institution. Dubet (2002, p. 9), situa a profissão entre aquelas que remetem ao trabalho sobre $o$ outro, ou seja,

[...] atividades assalariadas, profissionais e reconhecidas que visam explicitamente a transformar o outro, ou, conjunto das atividades profissionais que participam da socialização dos indivíduos.

Partindo do pressuposto de que o trabalho sobre o outro, em suas origens, foi concebido como um programa institucional, que designa particularmente um modo de socialização ou um tipo de relação com o outro, esse autor estabelece distinções entre a forma como se configurou o trabalho do professor primário e o do professor secundário. Chama a atenção, igualmente, para o fato de que mudanças nesse programa institucional condicionam mudanças na percepção que os professores possuem de seu trabalho docente e, consequentemente, de sua própria identidade profissional.

Desse ponto de vista, debruçamo-nos, num primeiro momento, sobre o processo de criação do Colégio, bem como sobre os modelos pedagógicos que serviram de referência para sua organização, tentando captar o programa institucional que informou sua criação. Considerando-se que, com a criação do Colégio, inicia-se, ao menos oficialmente, o ensino secundário entre nós, e levando-se igualmente em conta o caráter modelar proposto para ele, a discussão sobre os fins e objetivos estabelecidos para essa instituição específica, bem como sobre sua estrutura pedagógico-administrativa, é expressiva do que se está projetando como um programa institucional para o ensino secundário como um todo. 
$\mathrm{Na}$ segunda parte, desenvolvemos um estudo preliminar sobre a primeira geração de professores do Colégio, assim considerados os professores nomeados no período (1838-1847), no sentido de estabelecer uma caracterização geral. Buscamos retraçar as trajetórias profıssionais de alguns desses professores, interna e externamente ao Colégio, no intuito de apontar para algumas pistas que permitam identificar as bases de legitimação das identidades por eles construídas enquanto professores.

Nesse segundo momento, nosso principal interlocutor será outro sociólogo francês, Claude Dubar (1997), que concebe a profissionalização como um processo de socialização que se desenvolve ao longo de toda a vida do sujeito. Desse ponto de vista, a identidade profissional do professor se configura como o resultado, sempre instável e provisório, da mediação de múltiplas interferências: as relacionadas ao controle estatal e as que emanam da cultura institucional em que ele se encontra inserido, ambas interagindo com as identidades visadas pelo próprio sujeito. Particularmente importante, no caso, é a categoria proposta por Dubar de estratégias identitárias, que podem ser externas e internas à instituição e que procuraremos identificar.

Para esse autor, a identidade profissional possui, também, uma dimensão geracional, devendo-se, portanto, atentar para as características das gerações de professores, pois elas constituem uma referência importante em termos da historicidade desse processo identitário.

\section{O programa institucional do Colégio de Pedro II}

Foi-nos possivel levantar uma extensa e diversificada bibliografia sobre o Colégio de Pedro II, referente ao período que é objeto de nosso trabalho. De forma geral, essa bibliografia, tanto a de caráter memorialístico quanto a de caráter acadêmico (dissertações e teses, artigos em periódicos especializados), foi produzida por ex-professores ou ex-alunos do Colégio e tende a uma monumentalização de seu papel no processo de formação das elites imperiais.

Desse ponto de vista, ao analisarmos o que estamos chamando de programa institucional do Colégio, parece-nos importante estarmos atentos à possível defasagem entre o projeto ofıcial e sua incorporação pela própria parcela da sociedade à qual se destinava. Importa, de início, ter presente o contexto de criação do Colégio de Pedro II.

Souza (2010) articula a criação do Colégio ao processo de construção do Estado-nação do Império Brasileiro. Remetendo-se ao Ato Adicional à Constituição, de 1834 resultado, a seu ver, da aliança entre o Poder Imperial, sediado na Corte, e as oligarquias escravistas das províncias -, o autor afirma que o Império teve que buscar formas alternativas para garantir a centralização da gestão e o fez, entre outras coisas, por meio da instrução/ educação de seus membros e, em particular, dos cidadãos ativos. Assim, ao mesmo tempo em que, com o Ato Adicional, descentralizava-se a instrução, dando autonomia às províncias para a criação de instituições de ensino, o Império criava o Colégio de Pedro II para ser referência curricular e administrativa das instituições congêneres no país. ${ }^{3}$

A esse respeito é bastante significativo o discurso de Bernardo Pereira de Vasconcelos, proferido na aula inaugural do Colégio, em 25 de março de 1838. Vasconcelos (1999, p. 245) afırma que a criação do Imperial Colégio de Pedro II tem como objetivo

\section{[...] oferecer um exemplar ou norma aos que já se acham instituídos nesta capital por alguns particulares; convencido como está de que a educação colegial é preferível à educação privada.}

3- Importa destacar que o Colégio foi criado antes mesmo do chamado golpe da maioridade, juntamente com o Instituto Histórico e Geográfico Brasileiro (IHGB). 0 país achava-se imerso nas revoltas regenciais e a criação de instituições de caráter modelador, nesse contexto, é significativa. 
É particularmente sugestiva essa contraposição que se estabelece entre a educação colegial e a educação privada. Tratava-se, como afirma Souza (2010), de retirar das mãos das famílias, ou da Casa, na perspectiva de Mattos (1994), a educação dos futuros cidadãos ativos do Império.

Bernardo Pereira de Vasconcelos, à época Ministro da Justiça e do Império, foi o principal responsável pela criação do Colégio Pedro II, ou melhor, pela transformação do antigo Seminário de São Joaquim em "collégio de instruçcção secundária”, dedicado, segundo suas próprias palavras, "à mais perfeita educação da mocidade" (VASCONCELOS, 1999, p. 246). Conforme relata Carvalho (1999), Vasconcelos supervisionou as obras de reforma do antigo Seminário, escreveu o regulamento do novo Colégio e fez o discurso da abertura das aulas, marcado simbolicamente para o dia em que se comemorava o juramento da Constituição de 1824.

A respeito da criação do Colégio, cumpre questionar a versão ainda dominante na historiografia, que estabelece uma linha de continuidade entre as duas instituições (o Seminário e o Colégio), reproduzindo a versão oficial consagrada no texto legal. Sem sombra de dúvida, o Colégio Pedro II se configura como uma nova instituição, com um programa institucional radicalmente diferente da instituição que o antecedeu. 0 discurso oficial, bem como os artifícios de garantir certo número de vagas para os órfãos do Seminário, buscavam, certamente, calar a oposição que apontava para o caráter elitista da nova instituição. ${ }^{4}$

Quanto ao modelo seguido, afirma Vasconcelos (1999, p. 245), em seu discurso, que

[...] as regras consagradas no Regulamento não são teorias inexpertas; elas foram importadas de países esclarecidos, têm o cunho da observação, têm o abono da prática e deram o resultado de transcendente utilidade.

4 - A esse respeito, ver a fala de Vergueiro em discussão travada no Senado, acusando o governo de ter acabado com uma instituição para pobres e desvalidos e criado uma outra para os ricos e abastados. Essa fala está transcrita na dissertação de Penna (2008).
Segundo Bastos (2008), os estatutos do estabelecimento teriam sido elaborados a partir da consulta aos estatutos dos liceus da Prússia, da Alemanha e da Holanda, mas a autora ressalta a influência do sistema de educação adotado por Napoleão I. A referência à França, aliás, é recorrente na bibliografia estudada.

0 próprio Vasconcelos, em discurso proferido na Câmara dos Deputados, em 19 de maio de 1838, para se defender da acusação de que o Colégio tinha um caráter fradesco, afırmava:

0 discurso era meu mas o regulamento é alheio: em quase todas as suas disposições é copiado dos regulamentos dos colégios de França, apenas modificado por homens que gozam da reputação de sábios, e entendem o que deve alterar-se nas disposições desses estatutos. [...] esse defeito não cabe, ou não quadra ao regulamento. Segundo tenho ouvido, ou tenho lido, foi ele concebido ou restaurado por Napoleão Bonaparte, e o empenho desse legislador não era criar frades, mas criar militares. (apud HAIDAR, 2008, p. 98-99)

De qualquer forma, Rodrigues (2010) chama a atenção para a influência de outras experiências e, especialmente, dos colégios mantidos por congregações religiosas. Refere-se, sobretudo, ao Colégio Caraça, de Minas Gerais, fundado em 1820 por padres lazaristas, cujo Reitor à época, o padre Leandro Rebelo Peixoto e Castro, foi convidado por Vasconcelos para ocupar o cargo de Vice-Reitor do Colégio Pedro II. Esse caráter mais tradicional da instituição, afırmado no próprio discurso de Vasconcelos, fica claramente evidenciado quando se aborda a questão da opção pela forma e denominação de colégio.

Conforme assinala Haidar (2008), o Ato Adicional encontrou o ensino das humanidades totalmente fragmentado, principalmente no setor público. Apenas após a descentralização promovida por esse Ato criaram-se 
[...] os primeiros liceus provinciais graças à reunião de cadeiras avulsas existentes nas capitais das Províncias: o Ateneu do Rio Grande do Norte em 1835 os Liceus da Bahia e da Paraíba em 1836. (HAIDAR, 2008, p. 21)

\section{A autora afirma, entretanto, que}

[...] os liceus provinciais, que ao serem criados reduziam-se a um aglomerado de aulas avulsas funcionando em um mesmo edifício, conservavam, ainda em 1850, o mesmo caráter inorgânico. (HAIDAR, 2008, p. 21)

Com a criação do Colégio, pretendia-se marcar a diferença.

Gasparello (2002) reporta-se a essa questão. Começa por diferenciar os termos liceu e colégio, com base em Silva (1922), que atribui ao primeiro o sentido de aula de ensino científico, associando-o a uma concepção moderna e republicana, nos moldes franceses, de preocupação com a utilidade prática do secundário, enquanto o segundo termo estaria mais associado a uma concepção de cultura clássica e desinteressada.

De qualquer forma, ressalta a multiplicidade de termos atribuídos pelo poder público às instituições de ensino, no século XIX, bem como sua imprecisão. Esta viria a ser objeto de preocupação da Inspetoria Geral de Instrução da Corte, que em ofício dirigido ao Ministro, já em 1862, aponta para a necessidade de uma definição oficial dos termos aplicados às instituições de ensino pela administração pública.

Gasparello (2002) transcreve um longo trecho do Parecer de Conselheiro Calógeras (ex-professor do Colégio Pedro II) que serviu de base ao Aviso expedido sobre o assunto pelo Ministro, trecho este que nos parece interessante reproduzir também aqui, devido à sua relevância para nossa argumentação:

A maior ou menor idade de quem abre um estabelecimento de instrução deve-se exigir, não somente em relação ao ensino, mas também tendo em consideração se no estabelecimento os alunos recebem somente instrução, ou instrução e educação. Pois se é verdade que a multiplicidade e variedade das matérias exigem conhecimentos especiais para se saber dirigir não só os alunos, como também os professores, não é menos certo, e isto nos parece mais importante, que a educação exige maior seriedade e consciência da parte daquele que vem a ser como o pai de seus alunos.

Por isso, havendo alunos internos e meiopensionistas em um estabelecimento, seja qual for o número de professores e das matérias do ensino, o estabelecimento é um colégio, e deve-se exigir do professor ou diretor, a maioridade do artigo 102 (25 anos). ${ }^{5}$

Assim, pois, um professor de letras, um professor de uma ou mais matérias da instrução primária e secundária, e um estabelecimento com diretor e professores de várias matérias, em todas estas casas, havendo internos ou meio-pensionistas, o estabelecimento seja qual for o nome que lha derem seus donos, deve-se considerar como Colégio, e seu chefe deve ter 25 anos. E do mesmo modo, o estabelecimento com um Diretor e professores de várias matérias, ainda que seja freqüentado somente por externos, é Colégio.

Se, porém o estabelecimento é somente de primeiras letras, ou de uma ou mais matérias de instrução primária ou secundária, mas em ambas as casas havendo somente alunos externos, e um só professor que é ao mesmo tempo o chefe da casa, o estabelecimento é escola, e basta que seu chefe tenha os 21 anos. Porquanto nestas casas o chefe não tem de dirigir outros professores, ... e não tem de educar meninos. Nesta categoria compreendem-se naturalmente os estabelecimentos de instrução chamados aulas, cursos, ou de qualquer outro nome, em idênticas

5- Tratava-se, no caso, de definir com clareza a idade mínima exigida para um diretor de estabelecimento de ensino, prevista no Decreto de 1854. 
circunstâncias. (Processo de 18 de janeiro de 1862, apud GASPARELLO, 2002, p. 9)

Como assinala Gasparello (2002), tal Parecer define os critérios que permitem identificar um colégio, e o Pedro II teria todas essas características.

Até que ponto essa é a forma de organização que se impõe ao nascente ensino secundário? Algumas pistas puderam ser identificadas a partir da bibliografia estudada, as quais apontam para o que estamos considerando como uma expressão da resistência à institucionalização desse tipo de ensino em sua forma colegial, pela própria parcela da sociedade a quem se dirigia.

Uma primeira pista está dada por Haidar (2008), ao questionar o papel efetivamente exercido pelo Colégio Pedro II, ao longo do Império, enquanto colégio padrão. Para ela, o Colégio configurou-se, durante esse período, como um padrão apenas ideal, mas não real, tendo em vista sua coexistência com múltiplas formas de ensino secundário que adentraram a própria República: as aulas públicas avulsas; os liceus estaduais, que buscavam equiparar-se ao Colégio de Pedro II; os colégios particulares seriados; os colégios particulares que ofereciam apenas um conjunto de aulas isoladas nas quais os alunos podiam se matricular separadamente; as aulas de preparatórios anexas às instituições de ensino superior; e os exames parcelados de disciplinas isoladas, que persistiram no interior do próprio Colégio de Pedro II. A essas formas institucionalizadas de ensino, cumpre acrescentar a educação doméstica, que, até o final do Império, teve um peso significativo no processo de formação das elites, inclusive no âmbito da Corte. ${ }^{6}$

Silva (1969) ressalta a longa permanência dos exames parcelados de preparatórios, ${ }^{7}$ que adentraram a própria República, como um fator problemático no desenvolvimento do ensino

6 - A esse respeito, ver VASCONCELOS (2005).

7- Eram exames de disciplinas isoladas que habilitavam ao ingresso nos cursos superiores. secundário entre nós, e relaciona a questão à ausência de um lastro de tradição pedagógica que atribuísse a esse ensino uma finalidade em si mesmo, de caráter mais formativo, sendo ele exclusivamente percebido como uma preparação imediata e sumária para o ensino superior. Haidar (2008) afirma igualmente que essa função propedêutica atribuída quase que exclusivamente aos estudos secundários durante o Império acabou por reduzi-los a esses exames, estimulando os estudos fragmentários e irregulares.

De acordo com Silva (1967), tais exames passaram por três etapas ao longo do Império. De início, eram realizados exclusivamente nas instituições de ensino superior; a partir de 1851, são também realizados no Município da Corte, perante a Inspetoria de Instrução Primária e Secundária, criada nesse mesmo ano; depois, no Colégio de Pedro II: são os exames gerais de preparatórios. A partir de 1873, são realizados também nas províncias que não possuíam cursos superiores, diante de delegados do Inspetor de Instrução e de bancas indicadas pelos presidentes de província. Para o autor, essas mudanças indicam uma modificação na concepção de tais exames, que passam da condição de exames de ingresso nos cursos superiores a exames de conclusão do curso secundário. Para ele, porém, a questão problemática é que, mesmo no último caso, esses exames podem ser prestados parceladamente, diferenciando-se, portanto, de um exame de madureza, nos moldes do baccalauréat francês.

Haidar (2008) se demora longamente sobre a concorrência das aulas públicas avulsas, assinalando que, até 1853, estas contaram com uma matrícula superior à do Colégio, situação que se inverte a partir de então. No início de 1857 , às vésperas da sua extinção, ${ }^{8}$ havia apenas 19 alunos matriculados nessas aulas, contra 293 no Colégio. No entanto, avulta a concorrência dos colégios particulares, em que se matriculavam 1.697 alunos e 831 alunas.

8 - As aulas públicas avulsas de instrução secundária só foram extintas no Município da Corte pelo Decreto n² 2.006, de 24 de outubro de 1857. 
Outra questão, para a autora, são as matrículas avulsas por disciplinas no interior do próprio Colégio, autorizadas pelo Regulamento de 1855, situação agravada pela possibilidade criada em 1878 de que os alunos que não tivessem cursado as aulas do Colégio poderiam prestar exame vago de qualquer ou de todas as matérias oferecidas e até obter, dessa forma, o grau de bacharel em letras.

Com essa medida, segundo Haidar (2008, p. 139), multiplicaram-se tais matrículas e "a torrente avassaladora dos estudos avulsos, incessantemente alimentada pelos exames de preparatórios", desorganizou inteiramente os estudos no Colégio de Pedro II. Tal sistema acabou por instituir a frequência livre na área dos estudos preparatórios:

[...] cada um que estudasse onde e como quisesse e depois provasse nos exames, realizados na ordem que lhe aprouvesse, os conhecimentos adquiridos. (HAIDAR, 2008, p. 66)

A autora articula a isso a enorme evasão ao longo do curso, já que eram raros os alunos do Colégio que concluíam os estudos e chegavam ao bacharelado.

Pretende-se aprofundar essas questões num segundo momento, mas desde já se anuncia a necessidade de discutir a própria função propedêutica tradicionalmente atribuída pela historiografia referente ao período ao ensino secundário, já que este, em sua forma escolarizada, sequer era exigido para ingresso no ensino superior.

\section{A primeira geração de professores do Colégio Pedro II:} uma caracterização geral

$\mathrm{Na}$ segunda parte deste trabalho, desenvolvemos uma análise preliminar acerca dos primeiros professores do Colégio Pedro II. Trata-se de um grupo de 28 professores, divididos em duas categorias - efetivos (24) e mestres (4) - e nomeados no período entre 1838 e 1847 para ocuparem os respectivos cargos. ${ }^{9}$

De posse dos nomes desses professores, procuramos levantar o maior número de dados a respeito deles, de forma a identificar as respectivas trajetórias profissionais, interna e externamente ao Colégio. A esse respeito, duas fontes mostraram-se particularmente relevantes: os necrológios publicados na revista do IHGB e os anúncios do Almanak Laemmert. Mesmo assim, no caso de alguns desses professores, não conseguimos obter muitas informações além do fato de seus nomes serem citados em alguns trabalhos acadêmicos sobre o Colégio Pedro II.

Um aspecto inicialmente pesquisado foi o contexto de contratação dos 28 primeiros professores do Colégio de Pedro II. Como já se afirmou, segundo o artigo 12 do capítulo IV do Estatuto de 1838, eles deveriam ser selecionados pelo Ministro do Império.

A documentação encontrada, ainda em fase inicial de análise, aponta a existência de cartas enviadas ao Ministro do Império por postulantes ao cargo de professor do Colégio de Pedro II. No Setor de Manuscritos da Biblioteca Nacional, encontra-se, por exemplo, o registro do pedido feito em 1847 por Joseph Hermann, o Barão de Tautphoeus, para ocupar a Cadeira de Alemão do Colégio de Pedro II. ${ }^{10}$ Outro documento localizado é a carta de Santiago Nunes Ribeiro, de 1845, solicitando a propriedade da Cadeira de Retórica e Poética na mesma instituição. ${ }^{11}$ Há ainda indícios de que as indicações de novos professores também eram feitas por sugestão dos próprios professores do Colégio ou de demais membros da elite do Império. Em discurso pronunciado no IHGB, em 15 de dezembro de 1873, Joaquim Manuel de Macedo ${ }^{12}$ refere-se ao Dr. Joaquim Caetano da Silva, ex-professor do Colégio, nos

9- Utilizamos como fontes o Primeiro Livro de Empregados e o Anuário $N^{0} \mathrm{XV}$, encontrados no Núcleo de Documentação e Memória (NUDOM) do Colégio Pedro II.

10- Biblioteca Nacional. Setor de Manuscritos. Localização C-0774,053 nº 002

11- Biblioteca Nacional. Setor de Manuscritos. Localização C-1068,056.

12- Importante escritor brasileiro, foi professor de história do Colégio Pedro II. 
seguintes termos: "Sua primeira nomeação deveu-a a informações de illustres brasileiros, seus collegas em França; as outras à immediata e evidente demonstração do poder de suas faculdades" (MACEDO, 1873, p. 643). 0s dados biográficos levantados sobre esse primeiro grupo de professores apontam para a existência de laços de amizade entre alguns professores, anteriores à vinculação ao Colégio.

Como inexistiam instituições de formação de professores para o ensino secundário, buscamos identificar as qualificações consideradas quando de sua contratação. Ressaltam-se a passagem por instituições renomadas de ensino, o prestígio junto à elite intelectual brasileira e ligações com o mundo europeu civilizado, seja por nascimento ou pela via da instrução.

No livro Um passeio pela cidade do Rio de Janeiro, Joaquim Manuel de Macedo (2005, p. 321) faz referência à credibilidade que os professores escolhidos conferiam ao Colégio no início de seu funcionamento:

A simples menção dos nomes do reitor e dos professores com os quais se ia inaugurar o Imperial Colégio de Pedro II devia bastar para os primeiros fundamentos do crédito do estabelecimento. Porque, em geral eram os nomeados ou recomendáveis por sua capacidade já provada nas matérias que tinham de ensinar, ou por sua reconhecida ilustração, e alguns eram até com razão considerados notabilidades.

Entretanto, verificamos que, de início, o Colégio Pedro II parece ter encontrado dificuldades para que as cadeiras que compunham seu currículo fossem ocupadas. Podemos citar como exemplo o fato de que, dos primeiros 11 professores nomeados em 1838 para lecionar as matérias previstas, 7 permaneceram na instituição somente até o ano de 1839, o que representa 25\% dos professores efetivos investigados. Esse dado evidencia que, nos primeiros anos de funcionamento, tais professores ainda não tinham construído um vínculo significativo com o Colégio e que compromissos relacionados às outras atividades desenvolvidas, ou mesmo o fato de alguns serem de origem estrangeira, podem ter contribuído para essa não permanência na instituição.

Ao menos 7 dos 24 professores efetivos investigados tinham origem estrangeira, nascidos em países como Portugal, França, Alemanha, Chile e Argentina. Além disso, em sua maioria, os professores do Colégio de Pedro II cursaram algum grau de formação na Europa, especialmente nas Universidades de Coimbra, Paris e Montpellier, o que reforça a importância dos laços com os países civilizados. Dentre eles, ao menos 4 eram médicos, 1 era formado em Direito, 1 defendeu tese em Filosofia e 1 desenvolveu estudos em Humanidades. Além disso, os professores que fizeram os cursos superiores no Brasil, graduando-se em Medicina e Direito, tiveram docentes formados por instituições europeias. Desse ponto de vista, um elemento comum a todos era a base europeia de sua formação. Verificamos, ainda, que 4 professores eram religiosos, sendo 3 padres que ministraram aulas de religião e 1 cônego professor de geografia e história. Com relação aos títulos de nobreza, o Colégio Pedro II contava com 3 Barões (de Santo Angelo, de Planitz e de Tautphoeus - sendo este o único dos professores analisados a lecionar 3 disciplinas: alemão, grego e história) e com 1 Visconde (de Araguaya).

Alguns dos primeiros professores do Colégio Pedro II, como Manoel de Araujo Porto Alegre, Lino Antonio Rebello, Justiniano José da Rocha, Joaquim Caetano da Silva, Emilio Joaquim da Silva Maia, Joaquim Manoel de Macedo, Francisco de Paula Menezes e Tiburcio Antonio Chaveiro, foram também sócios efetivos e membros do IHGB.

A partir da investigação dos dados biográficos, foram percebidas outras similaridades nas trajetórias desses professores. Entre aqueles que assumiram o cargo entre de 1838 e 1847, 4 são identificados como precursores do Romantismo no Brasil: Justiniano José da Rocha, Dr. Domingos José de Magalhães, Manoel de 
Araújo Porto-Alegre e Santiago Nunes Ribeiro. Como observa Bosi (2012), a temática da natureza e a exaltação dos mitos fundacionais do país, presentes na obra desses autores, contribuíram para o projeto de construção de uma nacionalidade brasileira. Essa característica pode ter influenciado não só sua presença no Colégio, mas também sua participação como sócios e membros de importância do IHGB. Aliás, já ressaltamos anteriormente a afinidade entre essas duas iniciativas do governo imperial.

Podemos afirmar, em linhas gerais, que os primeiros professores do Colégio são donos de intensa produção intelectual, pois fundaram e escreveram para jornais e periódicos, publicaram compêndios, obras literárias, foram produtores de obras de arte e alguns são considerados fundadores de disciplinas escolares no Brasil, como é o caso de Manuel de Araújo Porto Alegre (desenho), que também publicou a primeira charge em periódicos do país, em $1837 .{ }^{13}$

Em relação às funções desempenhadas pelos professores no Colégio, estas não estavam vinculadas apenas às práticas em sala de aula. Eles participavam das bancas de seleção dos novos alunos e, em caso de aprovação, tinham que indicar em qual ano o aluno deveria ser matriculado. Faziam também as traduções dos compêndios estrangeiros que seriam usados em sala de aula, assim como podiam opinar acerca dos rumos da instituição. Um exemplo foi o pedido feito pelos professores para a manutenção do professor Domingos de Magalhães junto ao quadro de funcionários da instituição, transcrito a seguir:

[...] se devia ter todo o cuidado em conservar o professor Magalhães (o futuro Visconde de Araguaia), o Gênio da Filosofia, que não sendo ocupado em 1839, podia ser que

13- A charge envolvia, de maneira desprestigiosa, mais um dos primeiros professores do Colégio Pedro II, Justiniano José da Rocha, inimigo político de Manuel de Araújo Porto Alegre e, na época, diretor do jornal Correio Oficial, ligado ao governo. Ambos são nomeados professores do Colégio na mesma data, 8 de maio de 1838, saem da instituição igualmente na mesma data, 10 de maio de 1839, e podem ter levado suas disputas políticas do contexto externo para o contexto interno do Colégio. desviasse da ocupação para que tinha sido nomeado. (apud DORIA,1997, p. 42)

Embora os professores pudessem encaminhar demandas desse tipo, havia um controle rígido sobre suas atitudes. Cabia ao Ministro do Império e aos responsáveis pela instrução secundária controlar as faltas dos professores e exigir a justificativa das ausências. Em casos mais graves, poderiam encaminhar um pedido de afastamento para que os professores faltosos fossem prontamente substituídos. 0 artigo 136 do capítulo XXII do Estatuto de 1838 afirma que, uma vez ao ano, Comissários seriam enviados ao Colégio para observar as aulas e o comportamento dos professores. No capítulo IV do mesmo Estatuto, era previsto, em seu artigo 14, que os professores tinham que se vestir de forma decente e estar em sala de aula antes da chegada dos alunos. Já o artigo 15 alertava para o fato de que não poderiam aceitar retribuições ou receber presentes dos alunos. Além de serem homens ilustrados, era preciso que tivessem uma postura exemplar.

No decorrer da pesquisa, percebe-se que o Colégio de Pedro II conferia prestígio aos seus professores, que buscavam identificar-se como tal. No entanto, as primeiras análises demonstram que não só o Colégio era bastante criticado na imprensa em geral e passava por dificuldades de ordem material, como a questão salarial era considerada um problema por parte dos professores.

No primeiro ano de funcionamento da instituição, os salários eram diferenciados por cadeira e pela quantidade de aulas. Em 1838, os salários em algumas disciplinas eram os seguintes:

Quadro 1 - Salários dos professores em 1838

\begin{tabular}{ccc}
\hline Disciplina & Salário \\
\hline Latim & $\vdots$ & $500 \$ 000$ \\
\hline Grego & $\vdots$ & $500 \$ 000$ \\
\hline Aritmética & $\vdots$ & $500 \$ 000$ \\
\hline Geografia & $\vdots$ & $500 \$ 000$ \\
\hline Desenho & $\vdots$ & $400 \$ 000$ \\
\hline Música & $\vdots$ & $400 \$ 000$ \\
\hline Francês & $\vdots$ & $200 \$ 000$
\end{tabular}

Fonte: DORIA, 1997, p. 36 
Nos manuscritos encontrados na Biblioteca Nacional, são feitas referências a requerimentos de aumento de salário encaminhados por professores do Colégio de Pedro II ao Ministro do Império. Entre eles está o pedido enviado em 1842 pelos professores Diogo Maze, Francisco Maria Piquet e o Barão de Planitz (Carlos Roberto). ${ }^{14}$ Em 1844, o professor Maze pediu demissão da instituição em razão dos baixos vencimentos.

A questão salarial foi indiretamente abordada por Joaquim Manuel de Macedo em discurso no IHGB, por ocasião do falecimento do sócio e ex-professor de matemática do Colégio de Pedro II, Lino Antonio Rabello:

0 primeiro sorriso que se abriu na face da fortuna aos olhos do Dr. Lino Antônio Rabello accendeu-lhe n'alma ainda uma ilusão, que deveria tornar-se bem dolorosa na hora positiva di desengano. Em 1836 o nosso consocio foi nomeado lente substituto, e logo depois proprietário da escola de architectos medidores, que n'esse mesmo anno se installára na capital da provincia do Rio de Janeiro; em 1844 porém, uma nova lei provincial extinguiu aquella instituição, e o Dr. Lino Antonio Rabello, já sobrecarregado de família, achou-se reduzido ao triste recurso que lhe proporcionava o ordenado extremamente mesquinho, de professor de mathematicas do imperial collegio de Pedro II. (MACEDO, 1857 , p. 85$)^{15}$

Algumas formas de se aumentarem os rendimentos eram tomar conta dos alunos que fıcavam na instituição durante as férias, o que estava previsto no Estatuto do Colégio, ou, como dito anteriormente, fazer as traduções dos compêndios estrangeiros.

14 - Biblioteca Nacional. Setor de Manuscritos. Localização C-0020,040. 15- De acordo com Macedo (1857), a vida do professor Lino Antonio Rabello só melhorou após ele deixar o magistério e ser empregado como inspetor da Tesouraria da Província de Minas Gerais. No entanto, não foi 0 suficiente para que a família Rabello passasse a ter uma situação confortável.
A baixa remuneração dos professores era um problema reconhecido pelos próprios administradores do Colégio de Pedro II, como se pode depreender da citação abaixo:

Permita-me V. Exa. a observação de que se exige fixarem-se quanto antes os ordenados dos professores e dos principais empregados do Colégio porque se até julho eles não tiverem sido fixados o Colégio vem a perder um de seus mais acreditados professores o Dr. Joaquim Caetano da Silva, o qual é convidado para ir no Colégio de Jacuecanga na Ilha Grande ocupar duas cadeiras, vencendo por uma $800 \$ 000$, e por outra 400\$000, com jubilação passados 20 anos de ensino. (PADRE LEANDRO DE CASTRO RABELLO, 1839, apud DORIA, 1997, p. 42)

Os professores acerca dos quais obtivemos informações não eram funcionários exclusivos do Colégio de Pedro II. De acordo com as edições do Almanak Laemmert de 1844 e 1845, 5 deles também eram professores públicos da Corte: José Luiz Alves (professor público de inglês), Jorge Furtado de Mendonça (professor público substituto de latim), João de Castro Silva (professor de latim), Dr. Francisco de Paula Menezes (professor público de retórica) e Candido Matheus de Faria Pardal (professor público de primeiras letras). No exemplar de 1845, foram encontrados registros de 3 professores do Colégio que atuavam simultaneamente no Collégio Athenêo Fluminense: João Baptista Calógeras (diretor e professor de literatura italiana e história moderna), o Barão de Tautphoeus (professor de alemão e geografia) e Santiago Nunes Ribeiro (literatura portuguesa e literatura brasileira). Ainda, o almanaque anunciava o Padre Joaquim de Oliveira Durão como professor de dogma no Seminário Episcopal de São José. Na edição de 1847, foram identificados 2 professores do Colégio de Pedro II que atuavam no Collégio d'Instrucção Elementar: o Barão de Tautphoeus (professor de história universal) e Santiago Nunes Ribeiro (professor de geografia e cronologia). 
Tais professores também exerciam outras ocupações (advocacia, medicina, jornalismo, pintura, música), o que não surpreende, pois, como afirma Carvalho (2010), esse período do século XIX foi marcado pelo fenômeno da ocupação múltipla. Para o autor, a estrutura econômica brasileira de caráter agrário-exportadora e escravista limitava as oportunidades profissionais disponiveis. Com isso, as alternativas de trabalho eram poucas e os salários eram baixos.

O Colégio Pedro II contava ainda com 4 mestres, sendo 2 da disciplina música e 2 da disciplina ginástica. 0 compositor e cantor Francisco da Luz Pinto, que lecionou por 10 anos na instituição, e o compositor, organista e pianista Januário da Silva Arvellos foram os primeiros professores de música, enquanto Guilherme Luiz Taube e o espanhol Frederico Hoppe, que possuíam formação militar, foram os primeiros professores de ginástica do Colégio Pedro II. ${ }^{16}$ A diferença de denominação (mestres $\mathrm{x}$ professores) parece indicar uma hierarquização interna dos docentes. A esse respeito, Penna (2008, p. 112-113) assinala:

Curiosamente, a dança e a natação aparecem nos estatutos do Colégio ao lado da Música vocal e de "outros recreios" - esta associação parecendo agrupar os "recreios" em oposição à instrução intelectual. Apesar do discurso de que a Educação Física seria tão importante quanto a intelectual, a primeira seria trabalhada apenas nos feriados e considerada um recreio, enquanto a segunda seria trabalhada exaustivamente durante cinco dias da semana pela manhã e à tarde. Mas o fato de ser vista como um recreio não quer dizer que não fosse considerada importante, tanto que se tentou conseguir um prédio para se dedicar unicamente a ela.

16- Sobre os dois últimos, ver o trabalho de Cunha Júnior (2008) sobre o processo de escolarização da Educação Física no Brasil, a partir do Colégio Pedro II.
Segue a relação dos primeiros professores contratados até 1847.

Quadro 2 - Professores efetivos (até 1847)

\begin{tabular}{|c|c|c|c|}
\hline & Ano $^{*}$ & Nome & Matéria \\
\hline 1 & 1838 & Dr. Joaquim Caetano da Silva & Grego \\
\hline 2 & 1838 & $\begin{array}{l}\text { Manuel de Araújo Porto Alegre } \\
\text { (Barão de Sto Angelo) }\end{array}$ & Desenho \\
\hline 3 & 1838 & Francisco Maria Piquet & Francês \\
\hline 4 & 1838 & João de Castro Silva & Latim \\
\hline 5 & 1838 & Dr. Emílio Joaquim da Silva Maia & História natural \\
\hline 6 & 1838 & Dr. Justiniano José da Rocha & $\begin{array}{l}\text { Geografia e } \\
\text { história }\end{array}$ \\
\hline 7 & 1838 & $\begin{array}{l}\text { Dr. Domingos José Gonçalves de } \\
\text { Magalhães (Visconde de Araguaya) }\end{array}$ & Filosofia \\
\hline 8 & 1838 & Jorge Furtado de Mendonça & Latim \\
\hline 9 & 1838 & $\begin{array}{l}\text { Padre Leandro Rebello Peixoto e } \\
\text { Castro }\end{array}$ & Religião \\
\hline 10 & 1838 & Gabriel de Medeiros Gomes & Português \\
\hline 11 & 1838 & Padre Joaquim de Oliveira Durão & Religião \\
\hline 12 & 1839 & Diogo Maze & Inglês \\
\hline 13 & 1839 & Candido Matheos de Faria Pardal & Desenho \\
\hline 14 & 1839 & Lino Antonio Rabello & Matemática \\
\hline 15 & 1839 & Padre Manuel Antônio da Silva & Religião \\
\hline 26 & 1840 & Carlos Roberto (Barão de Planitz) & Alemão \\
\hline 17 & 1840 & Tiburcio Antonio Craveiro & Latim \\
\hline 18 & 1840 & $\begin{array}{l}\text { Conego Dr. Marcelino José da } \\
\text { Ribeira Silva Bueno }\end{array}$ & $\begin{array}{l}\text { Geografia e } \\
\text { história }\end{array}$ \\
\hline 19 & 1842 & Santiago Nunes Ribeiro & $\begin{array}{l}\text { Filosofia e } \\
\text { retórica }\end{array}$ \\
\hline 20 & 1843 & Bernardo Jose Falletti & Latim \\
\hline 21 & 1844 & José Luiz Alves & Inglês \\
\hline 22 & 1847 & João Baptista Calógeras & $\begin{array}{l}\text { Geografia e } \\
\text { história }\end{array}$ \\
\hline 23 & 1847 & $\begin{array}{l}\text { Joseph Hermann (Barão de } \\
\text { Tautphoeus) }\end{array}$ & $\begin{array}{l}\text { Alemão, grego e } \\
\text { história }\end{array}$ \\
\hline 24 & 1847 & Dr. Francisco de Paula N & $\begin{array}{l}\text { Filosofia e } \\
\text { retórica }\end{array}$ \\
\hline
\end{tabular}

Quadro 3 - Mestres (até 1847)

\begin{tabular}{|c|c|c|c|}
\hline & $\mathrm{Ano}^{*}$ & Nome & Matéria \\
\hline 25 & 1838 & Francisco da Luz Pinto & Música \\
\hline 26 & 1838 & Januário da Silva Arvellos & Música \\
\hline 27 & 1841 & Guilherme Luiz Taube & Ginástica \\
\hline 28 & 1846 & Frederico Hoppe & Ginástica \\
\hline
\end{tabular}

* De contratação. 


\section{Considerações finais}

Tendo em vista os objetivos a que nos propusemos, importa ter presente o que assinalamos ao início deste texto. Esse primeiro grupo de docentes do Colégio de Pedro II está se constituindo como professores de um ensino secundário nascente e no âmbito de uma instituição recém-criada, que procura simultaneamente conformar-se e impor-se como modelo para as instituições congêneres. Tal condição talvez possa explicar algumas características que ressaltamos aqui ao descrever brevemente as trajetórias de alguns desses professores, a começar pela relativa instabilidade desse grupo.

Embora exercessem simultaneamente outras atividades profissionais, como os demais membros da elite intelectual do Império, foi significativo constatar que alguns deles foram recrutados no âmbito do próprio magistério público, como é o caso dos 5 que eram também professores públicos da Corte. Havia ainda, como assinalamos, aqueles que acumulavam o magistério no Colégio com a docência em outras instituições de ensino. Pode-se citar, por exemplo, o caso do Barão de Tautphoeus, que atuava no Pedro II, no Collégio Athenêo Fluminense e no Collégio d'Instrucção Elementar, ministrando disciplinas tão diversas como alemão, grego, história e geografia. A situação talvez indique que, para alguns deles, o magistério já se configurava, ao menos, como uma ocupação principal. Nesse caso específico, talvez a condição de estrangeiro do Barão possa explicar sua opção.

Tais casos são também indicativos de outras tendências que, segundo pensamos, marcarão a forma como o magistério público secundário irá se constituindo até anos bem mais recentes. Em primeiro lugar, esses professores, particularmente aqueles que parecem se dedicar às atividades de ensino, circulam pelas diferentes instituições, sejam elas de caráter público (estatal) ou privado. São, em geral, instituições de prestígio no âmbito da boa sociedade, utilizando aqui a expressão cunhada por Mattos (1994).
A questão do prestígio precisa, a nosso ver, ser pensada numa via de mão dupla. Sem sombra de dúvida, parece-nos que esses primeiros professores foram escolhidos em razão do prestígio que poderiam conferir a uma instituição que procurava afirmar-se. Por outro lado, a instituição também confere prestígio aos professores, o que remete à tese de Nóvoa (1991) sobre o processo de funcionarização da profissão docente enquanto um processo sustentado simultaneamente pelo Estado e pelos próprios docentes. No caso específico do Colégio, parece-nos que esse prestígio está dado de fora e tem menos a ver com as condições efetivas de funcionamento da instituição do que com o papel atribuído a ela pelo Estado Imperial. Esse prestígio tem um peso significativo na permanência do professor na instituição, para além dos baixos salários e das condições precárias de funcionamento.

Outra questão importante e que se situa na contramão das análises desenvolvidas por Dubet (2002) sobre o caso francês é que o vínculo que o professor estabelece é com a instituição, e não com uma disciplina específica. A esse respeito, não só evidenciamos o caso-limite do Barão de Tautphoeus, como foi também significativo constatar a inexistência, ao menos com relação a esse grupo, de qualquer correspondência entre a área de formação do professor e a disciplina em que atua. Outro exemplo particularmente ilustrativo é a figura do professor substituto, previsto nos estatutos de 1838. Os substitutos, em número de 3 para todo o Colégio, poderiam substituir qualquer professor em qualquer disciplina, além de ensinar nas aulas que fossem subdivididas devido ao número de alunos.

Estas são reflexões iniciais, mas que confirmam nossa suposição de que conhecer o processo de construção das trajetórias desses primeiros professores do Colégio Pedro II, que subsidiaram a implantação do ensino secundário no Brasil, pode-se configurar em uma contribuição relevante para o campo da história da profissão docente. 


\section{Referências}

ANDRADE, Vera Lúcia Cabana de Queiroz. Colégio Pedro Il: um lugar de memória. Tese (Doutorado em História Social) - Instituto de Filosofia e Ciências Humanas, Universidade Federal do Rio de Janeiro, Rio de Janeiro, 1999.

BASTOS, Maria Helena Câmara. Manuais escolares franceses no Imperial Colégio de Pedro II (1856-1892). História da Educação, Pelotas, n. 26, p. 39-58, set./dez. 2008.

BOSI, Alfredo. Cultura. In: CARVALHO, José Murilo de Carvalho (Coord.). A construção nacional 1830-1889. Rio de Janeiro: Objetiva, 2012. p. 225-279.

BRASIL. Decreto-Lei de 2 de dezembro de 1837. In: Tribunaes, 1914. . Annuario do Collegio Pedro II. Rio de Janeiro: Typ. Revista dos

Anuário do Colégio Pedro II (1949-1950). v. XV. Rio de Janeiro: Ministério da Educação e da Cultura, 1954a.

Decreto n ${ }^{\circ}$ 1331-A, de 17 de fevereiro de 1854. In: Collecção das leis do Imperio do Brazil de 1854. Rio de Janeiro: Typographia Nacional, $1854 \mathrm{~b}$.

Decreto $n^{0}$ 2006, de 24 de outubro de 1857. In: Collecção das leis do Imperio do Brazil de 1857. Rio de Janeiro: Typographia Nacional, 1857.

CARVALHO, José Murilo de. Introdução. In: VASCONCELOS, Bernardo Pereira de. Bernardo Pereira de Vasconcelos. Organização e introdução de José Murilo de Carvalho. São Paulo: Ed. 34, 1999. Brasileira, 2010 .

A construção da ordem: a elite política imperial. Teatro das sombras: a política imperial. Rio de Janeiro: Civilização COLLEGIO PEDRO II. Primeiro livro dos empregados do Collégio Pedro II, 1838 a 1852.

COLÉGIO PEDRO II. Regulamento nº 8, de 31 de janeiro de 1838. Contém os Estatutos para o Colégio de Pedro Il. Internato. Órgão dos antigos e atuais alunos do Internato do Colégio Pedro II sob o patrocínio da Direção do Estabelecimento. Ano III, n. 3, jan. 1953.

CUNHA JÚNIOR, Carlos Fernando Ferreira. 0 processo de escolarização da educação física no Brasil: reflexões a partir do Imperial Collegio de Pedro Segundo (1841-1881). Revista HISTEDBR On-line, Campinas, n. 30, p. 59-83, 2008.

DORIA, Escragnolle. Memória histórica do Colégio de Pedro Segundo (1837-1937). 2. ed. Braślia: INEP, 1997.

DUBAR, Claude. A socialização: construção das identidades sociais e profissionais. Porto: Porto Editora, 1997.

DUBET, François. Le declin de l'institution. Paris: Éditions du Seuil, 2002.

GASPARELLO, Arlette M. Construtores de identidades: os compêndios de História do Brasil do Colégio Pedro II (1838-1920). Tese (Doutorado em Educação) - Pontifícia Universidade Católica, São Paulo, 2002.

Construtores de identidades: a pedagogia da nação nos livros didáticos da escola secundária brasileira. São Paulo: Iglu, 2004.

HAIDAR, Maria de Lourdes Mariotto. 0 ensino secundário no Brasil império. 2. ed. São Paulo: Edusp, 2008.

LAEMMERT, Eduardo; LAEMMERT, Henrique. Almanak administrativo, mercantil e industrial do Rio de Janeiro (Almanak Laemmert). Rio de Janeiro: Eduardo e Henrique Laemmert, 1844.

Almanak administrativo, mercantil e industrial do Rio de Janeiro (Almanak Laemmert). Rio de Janeiro: Eduardo e Henrique Laemmert, 1845.

Almanak administrativo, mercantil e industrial do Rio de Janeiro (Almanak Laemmert). Rio de Janeiro: Eduardo e Henrique Laemmert, 1847.

Almanak administrativo, mercantil e industrial do Rio de Janeiro (Almanak Laemmert). Rio de Janeiro: Eduardo e Henrique Laemmert, 1852.

MACEDO, Joaquim Manuel de. Um passeio pela cidade do Rio de Janeiro. Brasília: Senado Federal, 2005. 
MACEDO, Joaquim Manuel de. Discurso em homenagem a Lino Antonio Rabello. Revista Trimestral do Instituto Histórico Geográfico Brasileiro, Rio de Janeiro, p. 84-86, 1857. Disponível em: <http://www.ihgb.org.br/rihgb.php?s=19>. Acesso em: 5 abr. 2012.

. Discurso. Revista Trimestral do Instituto Histórico Brasileiro, Tomo XXXVI, p. 639-649, 1873. Disponível em: <http:// www.ihgb.org.br/rihgb.php?s=19>. Acesso em: 5 abr. 2012.

MATTOS, IImar R. Tempo saquarema. Rio de Janeiro: ACCESS, 1994.

NÓVOA, António. Para o estudo sócio-histórico da gênese e desenvolvimento da profissão docente. Teoria e Educação, Porto Alegre, n. 4, p. 109-139, 1991.

PENNA, Fernando A. Sob o nome e a capa do Imperador: a criação do Colégio de Pedro Segundo e a construção do seu currículo. Dissertação (Mestrado em Educação) - Faculdade de Educação, Universidade Federal do Rio de Janeiro, Rio de Janeiro, 2008.

RODRIGUES, Rafael Pinto. A educação literária no Colégio de Pedro II (1838-1854). Dissertação (Mestrado em História) Universidade Federal do Rio de Janeiro, Rio de Janeiro, 2010.

SILVA, Antonio de Moraes. Diccionario de lingua portuguesa. Fac-símile da segunda edição (1813). Edição Commemorativa do Primeiro Centenario da Independencia do Brasil. Photographada pela "Revista de Lingua Portuguesa". Sob a direção de Laudelino Freire. Rio de Janeiro: Officinas da S. A. Litho-Typographia Fluminense, 1922.

SILVA, Geraldo B. A educação secundária: perspectiva histórica e teoria. São Paulo: Editora Nacional, 1969.

SIRINELLI, Jean François. A geração. In: AMADO, Janaína; FERREIRA, Marieta de Moraes (org). Usos \& abusos da história oral. 8. ed. Rio de Janeiro: Editora FGV, 2006. p. 131-139.

SOUZA, Carlos Eduardo Dias. Ensinando a ser brasileiro: 0 Colégio Pedro Il e a formação dos cidadãos na Corte Imperial (18371861). Dissertação (Mestrado em História) - Pontifícia Universidade Católica, Rio de Janeiro, 2010.

VASCONCELOS, Bernardo Pereira de. Bernardo Pereira de Vasconcelos. Organização e introdução de José Murilo de Carvalho. São Paulo: Ed. 34, 1999.

VASCONCELOS, Maria Celi C. A casa e seus mestres: a educação no Brasil de Oitocentos. Rio de Janeiro: Gryphus, 2005.

VECHIA, Ariclê; LORENZ, Karl Michael (Orgs.). Programa de ensino da escola secundária Brasileira (1850-1951). Curitiba: Ed. Do Autor, 1998.

Recebido em: 18.01.2013.

Aprovado em: 07.06.2013.

Ana Waleska Pollo Campos Mendonça é professora de História da Educação dos cursos de graduação e pós-graduação do Departamento de Educação da Pontifícia Universidade Católica do Rio de Janeiro (PUC-Rio). É mestre e doutora em Educação pela mesma universidade, além de pesquisadora do CNPq.

Ivone Goulart Lopes é mestre em Educação pela Universidade Federal do Mato Grosso (UFMT) e doutoranda do Programa de Pós-Graduação em Educação da Pontifícia Universidade Católica do Rio de Janeiro (PUC-Rio). Atuou como professora no Colégio N.S. Auxiliadora (CG/MS), no Colégio Coração de Jesus (MT) e na Secretaria de Estado de Educação do Mato Grosso, como professora e gestora.

Jefferson da Costa Soares Patroclo é bacharel e licenciado em Ciências Sociais pela Universidade Federal do Rio de Janeiro (UFRJ), mestre em Educação pela mesma universidade, doutorando do Programa de Pós-Graduação em Educação da Pontifícia Universidade Católica do Rio de Janeiro (PUC-Rio) e bolsista Nota 10 da Fundação de Amparo à Pesquisa do Estado do Rio de Janeiro (FAPERJ).

Luciana Borges Patroclo é bacharel em Comunicação Social pela Pontifícia Universidade Católica do Rio de Janeiro (PUCRio), bacharel e licenciada em História pela Universidade Gama Filho (UGF), mestre em Educação pela Universidade Federal do Estado do Rio de Janeiro (UNIRIO), doutoranda do Programa de Pós-Graduação em Educação da PUC-Rio e bolsista do Conselho Nacional de Desenvolvimento Científico e Tecnológico (CNPq). 